\title{
REVIEW
}

\section{Dual HER2 blockade: preclinical and clinical data}

Tejal A Patel ${ }^{1,2}$, Bhuvanesh Dave ${ }^{1}$, Angel A Rodriguez ${ }^{1,2}$, Jenny C Chang ${ }^{1,2^{*}}$, Edith A Perez ${ }^{3}$ and Gerardo Colon-Otero ${ }^{3}$

\begin{abstract}
The estrogen receptor and human epidermal growth factor receptor (HER) signaling pathways are the dominant drivers of cell proliferation and survival in the majority of human breast cancers. Not surprisingly, targeting these pathways provides the most effective therapies in appropriately selected patients. However, de novo and acquired resistance remain major obstacles to successful treatment. By increasing the understanding of the molecular mechanisms of combined HER2-targeted therapies, we aim to be better able to select patients who would respond to these treatments and understand some of the mechanisms of resistance to HER2-targeted treatments. Recent studies have demonstrated an increased effectiveness of dual targeted HER2 therapies against HER2-amplified breast cancer as compared with single blockade. These studies have resulted in the recent US Food and Drug Administration approval of the combination of taxane chemotherapy with pertuzumab and trastuzumab in the first-line metastatic setting as well as an accelerated approval in the neoadjuvant setting. Another mechanism for overcoming resistance to HER2 targeted therapies is the antibody-drug conjugate trastuzumab-emtansine, which targets the HER2 receptor conjugated to the potent antimicrotubule agent mertansine, allowing for intracellular release of the cytotoxic drug. Studies evaluating the efficacy of dual blockade with antibody-drug conjugate are currently ongoing. This article reviews recent data on different combinations of anti-HER2 treatments as well as ongoing and future research in this area.
\end{abstract}

\footnotetext{
* Correspondence: jcchang@houstonmethodist.org

${ }^{1}$ Houston Methodist Cancer Center, 6445 Main Street, P21-34, Houston, TX 77030, USA

2Department of Medicine, Weill Cornell Medical College, 1300 York Avenue, New York, NY 10065, USA

Full list of author information is available at the end of the article
}

\section{Introduction}

Recognition of the impact of human epidermal growth factor receptor (HER)-2 overexpression or amplification in approximately 15 to $20 \%$ of all cases of invasive breast cancer has resulted in the development of multiple drugs that inhibit the proliferative signal pathway associated with this molecular alteration. The incorporation of HER2-directed therapy has improved the overall survival (OS) of metastatic breast cancer (MBC) patients by greater than $20 \%$ and has increased the cure rate of breast cancer in the adjuvant setting by approximately 30 to $40 \%[1,2]$. Despite this, approximately 5,000 patients with HER2overexpressing breast cancer die each year in the USA [3].

The HER family of transmembrane type I receptor tyrosine kinases includes four receptors (HER1 to HER4) that play an important role in cell processes including cell proliferation and survival. HER2 does not require ligand activation and can form homodimers or can interact with the other HER family receptors by forming heterodimers that lead to the activation of the HER2 tyrosine kinase. HER3 has only a weak intrinsic tyrosine kinase activity that activates HER2 by forming heterodimers with HER2, leading to the strongest preclinical mitogenic signals of all possible HER receptor dimer combinations [4]. Upon ligand binding to the active domain of HER1, HER3 or HER4, these receptors can activate homodimeric or heterodimeric receptor complexes - but they preferentially recruit HER2 into a heterodimeric complex in which the HER2 kinase can modulate receptor internalization and prolong signal transduction. Conformational changes occur upon dimerization, leading to autophosphorylation and initiation of divergent signal transduction cascades [5]. These signaling pathways from these receptor heterodimers are not absolutely linear and some of their functions may overlap; laboratory data generally indicate that HER1/HER2 heterodimers activate cell proliferation by the extracellular signal-regulated kinase 1/2-mitogen-activated protein kinase pathway [6], while HER2/HER3 heterodimers predominantly activate the phosphoinositide-3-kinase (PI3K)/AKT cell survival pathway [7]. 


\section{Approved HER2-targeted drugs for the treatment of HER2-positive breast cancer}

Several drugs have been developed and are in clinical use to block the HER pathway, most aimed at the receptor level.

Trastuzumab, a monoclonal antibody directed against HER2, became the first HER2-directed therapy for MBC and the first monoclonal antibody against cancer approved by the US Food and Drug Administration (FDA) in 1998 [2]. Trastuzumab has been theorized to induce cell death in HER2-overexpressing breast cancer cells by multiple mechanisms including antibody-dependent cellmediated cytotoxicity, induction of apoptosis and inactivation of HER2-mediated cell proliferation signaling [3]. A phase III clinical trial showed the effectiveness of trastuzumab in synergizing with chemotherapy by increasing the response rate and improving the OS of patients with $\mathrm{MBC}$ when compared with chemotherapy alone [2]. Trastuzumab is also commonly used in the refractory metastatic setting in combination with a wide range of chemotherapy agents. Use of trastuzumab is also pivotal to patient management in the adjuvant setting, as it improves disease-free survival (DFS) and OS when added to chemotherapy [1].

Lapatinib is an orally active dual HER1/HER2 kinase inhibitor that blocks signal transduction pathways. Lapatinib reduces tyrosine phosphorylation of HER1 and HER2, as well as activation of extracellular signal-regulated kinase 1/2-mitogen-activated protein kinase and PI3K/AKT, affecting downstream effectors of both proliferation and survival [8]. Lapatinib has demonstrated activity in patients with HER2-overexpressing MBC after escape from trastuzumab and is currently approved as second-line therapy for MBC patients after trastuzumab failure $[9,10]$. However, comparative phase III trials of chemotherapy with either trastuzumab or lapatinib suggested that trastuzumab was the optimal anti-HER2 therapy to select in this first-line $\mathrm{MBC}$ setting.

Pertuzumab, a recombinant humanized monoclonal antibody (2C4), binds to extracellular domain II of the HER2 receptor and blocks its ability to dimerize with other HER receptors, in particular HER2-HER3 complexes [11]. Pertuzumab was approved in combination with chemotherapy and trastuzumab for the first-line treatment of HER2-positive MBC and for the neoadjuvant therapy of HER2-positive breast cancer, based on data demonstrating improvement in progression-free survival and OS as compared with trastuzumab-based chemotherapy in patients with $\mathrm{MBC}$ and a higher rate of pathological complete remissions in the neoadjuvant setting [12].

In addition to these receptor targeted therapies, a new class of antibody-drug conjugate (ADC) has recently shown superior clinical activity. Ado-trastuzumab-emtansine
(T-DM1) is an ADC that incorporates the HER2-targeted antitumor properties of trastuzumab with the cytotoxic activity of the microtubule-inhibitory agent mertansine (derivative of maytansine); the antibody and the cytotoxic agent are conjugated by means of a unique stable linker. T-DM1 allows intracellular drug delivery specifically to HER2-overexpressing cells, thereby improving the therapeutic index and minimizing exposure of normal tissue. T-DM1 has demonstrated survival and superior tolerability over the lapatinib/capecitabine combination in the refractory HER2-positive advanced setting, and has received regulatory agency approval for such situations [13,14].

Table 1 presents the pivotal trials leading to US FDA approval of the different drugs targeting HER2 and the different approved combinations. This approval has converted a disease that had the worst prognosis of all breast cancer subtypes into one with the best prognosis. Of interest is the fact that only a minority of breast cancer cases (20\%) benefit from these treatments, which implies that these treatments may not have been proven to be of benefit if they had been applied to all breast cancer patients instead of being limited to the HER2-amplified subset, illustrating the importance of appropriate patient subset selection based on the biology of the tumor for successful drug discovery and development.

Despite the success of these agents that target the HER family as single agents, there are a number of escape mechanisms from HER-targeted therapies. Clinically, a more complete blockade of the HER receptor layer has been shown to be therapeutically meaningful in prolonging survival in patients. With incomplete blockade of the receptor input layer, proliferative and survival signals can be generated from several different dimer pairs. The idea that the redundancy in the input layer of the network might provide an escape mechanism around a singleagent block has been explored in preclinical trials and neoadjuvant trials as well as in adjuvant trials. Dual HER2 blockade is defined as a more complete blockade of the HER2 and HER signaling pathway by combining two inhibitors with complementary mechanisms of action. In this article, we will review the data supporting these findings and the plans for further evaluation of dual HER2 blockade.

\section{Why is dual HER2 blockade more effective than single-drug blockade: causes of resistance to single-agent HER2 blockade}

Despite the success in $\mathrm{MBC}$, responses to single-agent trastuzumab are limited and cancer will eventually progress. Many patients treated with adjuvant trastuzumab will be cured of the disease, but disease will recur in some of them. This suggests that both de novo and acquired mechanisms of drug resistance exist. Several possible 
Table 1 Chronological summary of US Food and Drug Administration approved anti-HER2 treatments in HER2-amplified breast cancer

\begin{tabular}{lllll}
\hline Year of approval & Cancer stage & Agent & Study name & Chemotherapy \\
\hline $1998[2]$ & First-line metastatic & T & - & Pac or AC \\
$1998[2]$ & Second-line and third-line metastatic & T & - & None \\
$2006[1,15]$ & Adjuvant & T & B31/N9831/BCIG006 & AC $\rightarrow$ Pac, TCH \\
$2006[16]$ & Metastatic & L & - & Capecitabine \\
$2009[17]$ & Metastatic & L+Al & TAnDEM & None \\
$2012[18]$ & Metastatic & P + T & CLEOPATRA & Docetaxel \\
$2013[13]$ & Metastatic & TDM-1 & EMILIA & None \\
$2013[19]$ & Neoadjuvant & P + T & NeoSphere & FEC $\rightarrow$ Pac, TCH \\
\hline
\end{tabular}

$\mathrm{Al}$, aromatase inhibitor; $\mathrm{AC}$, doxorubicin and cyclophosphamide; $\mathrm{FEC}$, fluorouracil, epirubicin, cyclophosphamide, HER, human epidermal growth factor receptor; L, lapatinib; P, pertuzumab; Pac, paclitaxel; T, trastuzumab; TCH, docetaxel, carboplatin and trastuzumab; TDM-1, ado-trastuzumab emtansine.

causes of resistance to both trastuzumab and lapatinib have been identified in preclinical studies. Few of these have been prospectively validated in clinical trials. There is enough indication to suggest that some of them do limit the effectiveness of HER2-directed therapy, particularly when these agents are used as single agents.

Some of the proposed mechanisms for resistance to trastuzumab include incomplete blockade of heterodimeric signaling or increased signaling through alternative signal transduction pathways, including upregulation of ligands or the receptors themselves [20], constitutive activation of the PI3K/Akt pathway due to loss of phosphatase and tensin homolog (PTEN) or activating mutations of PI3KCA or amplification of cyclin E [21,22], increased transforming growth factor-alpha expression, and the presence of altered forms of HER2 [23,24], which inhibits HER2-trastuzumab interactions. Escape pathways such as estrogen receptor (ER) or insulin-like growth factor receptor signaling have also been implicated in resistance. The data regarding PTEN loss and PI3K mutation and trastuzumab have been conflicting. Preclinical and smaller clinical studies have suggested PTEN loss associated with resistance to trastuzumab [25], although a larger study $(n=1,082)$ did not find an impact on DFS [26].

Mechanisms for lapatinib resistance are less well established and are hypothesized to include increased expression of AXL, a membrane-bound receptor tyrosine kinase with transforming ability [27], enhanced ER signaling through transcription factor FOXO3a [28], and upregulation of HER3 transcription [20]. There are discordant data with regards to PTEN loss and PI3K mutation and use of lapatinib in preclinical and small clinical studies [25,29].

The existence of resistance to trastuzumab and the development of resistance after exposure to trastuzumab are the main reasons for recurrences. Enhanced blockade of HER2 signaling with dual HER2 therapies may result in decreased recurrences and ultimately improve survival.

\section{Evidence for improved activity of combination anti-HER2 therapy}

Numerous recent and ongoing multicenter studies have focused on the benefits and toxicity of adding singleagent or dual HER2 targeting to chemotherapy. In the neoadjuvant setting, almost all of the trials used a chemotherapy backbone (taxane only or anthracycline/taxane or taxane/platinum), with the exception of TBCRC 006 and a subset of patients treated on NeoSphere that only included the targeted therapies without chemotherapy. Using combinations of inhibitors (for example, trastuzumab with pertuzumab or lapatinib with trastuzumab), higher responses with higher pathologic complete responses (pCRs) have been observed (Tables 2 and 3).

\section{Lapatinib and trastuzumab}

\section{Preclinical MCF-7/HER2 mouse xenograft studies}

Trastuzumab, pertuzumab, lapatinib and gefitinib represent a group of therapeutic agents that target the HER family by different molecular mechanisms. These drugs, when used as single agents in the MCF7/HER2-18 xenograft model, restored or enhanced sensitivity to tamoxifen. However, tumor growth inhibition lasted only 2 to 3 months before resistance to treatments occurred and tumor growth resumed. Preclinical studies in animal models evaluating the efficacy of various drug combinations have shown that the combination HER-targeting therapy with estrogen deprivation more effectively induced apoptosis, reduced levels of $\mathrm{p}$-AKT and mitogen-activated protein kinase, inhibited proliferation and was capable of eradicating HER2 overexpressing xenografts in mice [30,31]. Based on these results, neoadjuvant studies with trastuzumab and lapatinib together with estrogen deprivation were designed (TBCRC 006, see below) [32].

\section{Clinical studies}

In the metastatic setting, a phase III clinical trial comparing lapatinib versus lapatinib and trastuzumab in 296 patients who had progressed on a trastuzumab-containing 
Table 2 Published or presented multicenter neoadjuvant trials in HER2-positive disease including lapatinib

\begin{tabular}{|c|c|c|c|c|c|c|c|}
\hline Study & Neoadjuvant regimen & $\begin{array}{l}\text { pCR breast } \\
\text { and lymph } \\
\text { node T (\%) }\end{array}$ & $\begin{array}{l}\text { pCR breast } \\
\text { and lymph } \\
\text { node } L(\%)\end{array}$ & $\begin{array}{l}\text { pCR breast } \\
\text { and lymph } \\
\text { node } \\
\text { combination } \\
\mathrm{T}+\mathrm{L}(\%)\end{array}$ & $\begin{array}{l}\text { pCR breast and } \\
\text { lymph node } \\
\text { combination } \\
\mathrm{T}+\mathrm{L} \text { without } \\
\text { chemotherapy }(\%)\end{array}$ & Compliance & Statistical significance \\
\hline $\begin{array}{l}\text { NeoALTTO } \\
{[12,34]}\end{array}$ & $\begin{array}{l}6 \text { weeks } T \text { and/or } L \rightarrow \\
\text { WP } \times 12 \text { weeks plus } T \\
\text { and/or } L(n=455)\end{array}$ & 27.6 & 20 & 46.8 & NA & $\begin{array}{l}93 \% T_{1} \\
66 \% L_{1} \\
61 \% T+L\end{array}$ & $\begin{array}{l}\text { Between } \mathrm{T}+\mathrm{L} \text { and } \mathrm{T}, \\
P=0.0007\end{array}$ \\
\hline $\begin{array}{l}\text { CHER-LOB } \\
{[35]}\end{array}$ & $\begin{array}{l}\text { WP } \times 12 \text { weeks } \rightarrow \mathrm{FEC} \times 4 \\
\text { every } 3 \text { weeks plus T } \\
\text { and/or } \mathrm{L} \text { throughout } \\
(n=121)\end{array}$ & 25 & 26.3 & 46.7 & NA & $\begin{array}{l}\text { NR T, } 69 \% L, \\
83 \% T+L\end{array}$ & $\begin{array}{l}\text { No comparisons among } \\
\text { treatment regimens } \\
\text { planned. Exploratory } \\
\text { analysis between } T+L \text { vs. } T \text {, } \\
\text { risk ratio }=1.81, P=0.019\end{array}$ \\
\hline $\begin{array}{l}\text { NSABP } \\
41[36]\end{array}$ & $\begin{array}{l}\mathrm{AC} \times 4 \rightarrow \mathrm{WP} \times 12 \text { weeks } \\
\text { plus } \mathrm{T} \text { and/or } \mathrm{L}(n=519)\end{array}$ & 49.4 & 47.7 & 60.2 & NA & $\begin{array}{l}77 \% \mathrm{~T}_{1} \\
65 \% \mathrm{~L}_{,} \\
63 \% \mathrm{~T}+\mathrm{L}\end{array}$ & $\begin{array}{l}\text { Between } T+L \text { vs. } T, P=0.056 \\
\text { between } L \text { vs. } T, P=0.78 ; \text { not } \\
\text { significant }\end{array}$ \\
\hline $\begin{array}{l}\text { CALGB } \\
40601[37]\end{array}$ & $\begin{array}{l}\text { WP } \times 16 \text { weeks plus T } \\
\text { and/or } L(n=299)\end{array}$ & 43 & 29 & 52 & NA & $\begin{array}{l}93 \% T_{1} \\
66 \% L_{1} \\
87 \% T_{+} L\end{array}$ & $P=0.11 ;$ not significant \\
\hline $\begin{array}{l}\text { TRIO US } \\
\text { B07 [38] }\end{array}$ & $\begin{array}{l}\text { T and/or } L \times 21 \text { days } \rightarrow \\
\text { TCH } \times 6 \text { cycles plus } T \\
\text { and/or } L \text { throughout } \\
(n=130)\end{array}$ & 47 & 25 & 52 & NA & $\begin{array}{l}100 \% \mathrm{~T} \\
72 \% \mathrm{~L} \\
73 \% \mathrm{~T}+\mathrm{L}\end{array}$ & $\begin{array}{l}\text { Between } T+L \text { vs. } L, P=0.02 \\
\text { between } T \text { and } L, P=0.07\end{array}$ \\
\hline $\begin{array}{l}\text { TBCRC } \\
006[32]\end{array}$ & $\begin{array}{l}\text { T and } L \times 12 \text { weeks; } E R+ \\
\text { letrozole } \pm G(n=66)\end{array}$ & NA & NA & NA & 22 & $N R$ & Single-arm study \\
\hline $\begin{array}{l}\text { LPT } \\
109096[39]\end{array}$ & $\begin{array}{l}2 \text { weeks } T \text { and/or } L \rightarrow \text { FEC } \\
75 \times 4 \text { every } 3 \text { weeks } \rightarrow \\
\text { WP } \times 12 \text { weeks }+T \\
\text { and/or } L \text { throughout } \\
(n=100)\end{array}$ & 54 & 45 & 74 & NA & NR & $\begin{array}{l}\text { Not powered to compare } \\
\text { responses between arms }\end{array}$ \\
\hline
\end{tabular}

AC, adriamycin, cyclophosphamide; ER, estrogen receptor; FEC, fluorouracil, epirubicin, cyclophosphamide; G, goserelin; HER, human epidermal growth factor receptor; L, lapatinib; NA, not applicable; NR, not reported; pCR, pathologic complete response; T, trastuzumab; TCH, docetaxel, carboplatin and trastuzumab; WP, weekly paclitaxel.

regimen demonstrated an improvement in progressionfree survival (hazard ratio (HR), 0.73; 95\% confidence interval, 0.57 to $0.93 ; P=0.08)$ and a trend towards improved OS (HR, 0.75; 95\% confidence interval, 0.53 to $1.07 ; P=0.106)$ in patients receiving the combination [33]. This observation provided further evidence for combined HER2 blockade as well as continued use of trastuzumab beyond disease progression.

Six randomized neoadjuvant trials and one nonrandomized neoadjuvant trial as well as one adjuvant trial have evaluated the role of dual targeted therapies with lapatinib and trastuzumab (Table 2). Two large studies were conducted with a taxane-only backbone with anthracycline chemotherapy given after surgery. In the phase III study of NeoALTTO, 455 patients received paclitaxel with lapatinib, trastuzumab or the combination [12]. The dual-therapy arm had significantly improved pCR in the breast and axilla compared with trastuzumab alone $(46.8 \%$ vs. $27.6 \%, P=0.0007)$ [12]. The pCR rates were higher in patients with hormone receptor-negative tumors than those of hormone receptor-positive tumors in all groups (61.3 vs. $41.6 \%)$. A recent update of the study

Table 3 Published or presented multicenter neoadjuvant trials in HER2-positive disease including pertuzumab

\begin{tabular}{|c|c|c|c|c|c|c|}
\hline Study & Neoadjuvant regimen & $\begin{array}{l}\text { pCR breast } \\
\text { and lymph } \\
\text { node } T(\%)\end{array}$ & $\begin{array}{l}\text { pCR breast } \\
\text { and lymph } \\
\text { node } P(\%)\end{array}$ & $\begin{array}{l}\text { pCR breast and } \\
\text { lymph node } \\
\text { combination } \\
T+P(\%)\end{array}$ & $\begin{array}{l}\text { pCR breast and lymph } \\
\text { node combination } \\
\mathrm{T}+\mathrm{P} \text { without } \\
\text { chemotherapy (\%) }\end{array}$ & Statistical significance \\
\hline NeoSphere [19] & $\mathrm{D} \times 4$ with $\mathrm{T}$ and/or $\mathrm{P}$ & 21.5 & 17.7 & 39.3 & 11.2 & $\begin{array}{l}N R \text { for } p C R \text { breast and } \\
\text { lymph node. For } P C R \text { breast } \\
\text { only between } T+P \text { and } T \text {, } \\
P=0.0141\end{array}$ \\
\hline TRYPHAENA [43] & $\begin{array}{l}\text { Arm A, FECPH } \rightarrow \text { DPH; Arm B, } \\
\text { FEC } \rightarrow \text { DPH; Arm C, TCHP }\end{array}$ & 50.7 & 45.3 & 51.9 & NA & $\begin{array}{l}\text { Primary endpoint was } \\
\text { cardiac safety, } P \text { value NR }\end{array}$ \\
\hline
\end{tabular}

D, docetaxel; DPH, docetaxel, pertuzumab and trastuzumab; FEC, fluorouracil, epirubicin, cyclophosphamide; FECPH, fluorouracil, epirubicin, cyclophosphamide, pertuzumab and trastuzumab; HER, human epidermal growth factor receptor; NA, not applicable; NR, not reported; P, pertuzumab; pCR, pathologic complete response; T, trastuzumab; TCHP, docetaxel, carboplatin, trastuzumab and pertuzumab. 
demonstrated that patients who achieved pCR had significantly better event-free survival (EFS) (86\% vs. 72\%; HR, $0.38 ; P=0.003)$ and OS (94\% vs. $87 \%$; HR $0.35 ; P=0.005)$ compared with no pCR [34]. These results did not address the question of whether the higher $\mathrm{pCR}$ rate achieved with dual therapy translated into better EFS or OS because the NeoALTTO trial was underpowered to detect moderate differences in EFS and OS.

The adjuvant study ALTTO did not meet the primary endpoint of improved DFS with the addition of lapatinib to trastuzumab compared with trastuzumab as adjuvant treatment for HER2-positive early breast cancer [40]. ALTTO has raised questions regarding the use of an increase in pCR rate as a surrogate endpoint for improved DFS in the adjuvant setting and the effect of dual blockade on long-term outcome. ALTTO demonstrates that a large proportion of patients with HER2-positive early breast cancer do not derive benefit with dual blockade of lapatinib and trastuzumab. Whether a benefit exists in a higher risk population or in a subset of patients identified by a biomarker or a different dual blockade should be further evaluated. APHINITY is an adjuvant trial evaluating dual blockade of pertuzumab and trastuzumab versus trastuzumab in a high-risk population (node-positive) and will further answer the question regarding the benefit of dual blockade.

The CALGB 40601 trial randomized 305 patients to receive weekly paclitaxel for 16 weeks with trastuzumab alone or with the combination trastuzumab and lapatinib [37]. The pCR rate in the breast and axilla was numerically higher at $52 \%$ with the combination compared with $43 \%$ for the chemotherapy and trastuzumab arm, but was not statistically significant. This could have been due to underlying differences in the study population and highlights the need to identify tumors that can benefit with dual versus single HER2 targeting, possibly looking at the hormone receptor differences.

Three studies have evaluated the combination of lapatinib and trastuzumab with similar chemotherapy backbone of taxane followed by anthracycline-containing chemotherapy. The CHER-LOB study of 121 patients demonstrated near doubling of pCRs with dual HER2 targeting (47\% vs. $25 \%, P=0.019)$ compared with trastuzumab alone [35]. LPT 109096 included 100 patients and demonstrated a significantly higher pCR rate for the combination (74\% vs. $54 \%$ ) compared with trastuzumab alone [39]. A larger randomized phase III trial, NSABP B41, enrolled 529 patients and demonstrated numerically but not statistically improved breast and lymph node pCR for the combination arm versus trastuzumab (60.2\% vs. $49.4 \%, P=0.056)$ [36].

The TRIO US B07 study randomized 130 patients to treatment with a chemotherapy backbone of docetaxel and carboplatin and trastuzumab, lapatinib or both. The primary endpoint was the $\mathrm{pCR}$ rate in the breast and axilla (trastuzumab 47\%, lapatinib 25\%, combination 52\%) [38].

Finally, the nonrandomized window-of-opportunity study TBCRC 006 treated 66 patients with the combination trastuzumab and lapatinib without a chemotherapy backbone for 12 weeks [32]. Women with ER-positive tumors also received letrozole (plus a luteinizing hormonereleasing hormone agonist if premenopausal). Overall, the pCR rate for the breast and axilla was 22\% (ER-negative, 28\%; ER-positive, 18\%). Future studies are needed to identify a subset of HER2-positive breast cancer patients who may not need chemotherapy and can be treated with more complete blockade of HER receptors.

\section{Pertuzumab and trastuzumab}

One proposed cause for resistance to trastuzumab and lapatinib is the overexpression of HER3 in response to tyrosine kinase inhibition [20]. HER3 activation by binding its ligand results in a conformational change of HER3 with the formation of heterodimers with HER2. The formation of HER2-HER3 heterodimers leads to the activation of the PI3K signaling pathway and subsequent increase in cell proliferation and survival. In preclinical models, pertuzumab and trastuzumab combination demonstrated enhanced antitumor activity when compared with each agent alone and in tumors progressing on trastuzumab in HER2-positive breast xenografts [41]. The studies also demonstrated a sustained ( $>99$ days) prevention of metastatic tumor spread to the lungs and liver with the combination in the KPL-4 xenograft model; monotherapy did not prevent these metastases [41].

\section{Clinical studies}

In the metastatic setting, a phase III trial (CLEOPATRA) of docetaxel and trastuzumab with or without pertuzumab as first-line treatment for 808 patients with HER2-positive MBC showed a significant improvement in progressionfree survival and OS with the addition of pertuzumab $[18,42]$. A significant prolongation of progression-free survival was observed in the pertuzumab group ( $\mathrm{HR}, 0.62$; $P<0.001)$ with acceptable toxicity. As a result of this study, in 2012 the US FDA approved the use of pertuzumab in the first-line metastatic setting. The OS was updated in 2013; the median OS was 37.6 months in the placebo group and was not yet reached in the pertuzumab group (HR, 0.66; $P=0.0008$ ) [18].

Two neoadjuvant phase II studies have evaluated the addition of pertuzumab to various chemotherapy backbones (Table 3). NeoSphere is a four-arm randomized multicenter, open-label, phase 2 study of neoadjuvant therapy in 417 patients and compares single-agent trastuzumab or pertuzumab with docetaxel or the combination of trastuzumab and pertuzumab with or without docetaxel for four cycles [19]. The patients given pertuzumab and 
trastuzumab with docetaxel had significant improvement in breast pCR compared with the docetaxel and trastuzumab only arm ( $46 \%$ vs. $29 \%, P=0.0141)$ as well as in the breast and lymph node pCR (39.3\% vs. $21.5 \%)$. Consistent with previous studies, a lower pCR rate was noted for hormone receptor-positive patients compared with hormone receptor-negative tumors (26\% vs. $63 \%$ ). The combination targeted therapies only arm also had a $16.8 \%$ breast-only pCR rate and an $11.2 \%$ breast and lymph node pCR rate [19].

TRYPHAENA, an open-label, phase II study, randomized 225 patients to neoadjuvant chemotherapy with either: fluorouracil, epirubicin and cyclophosphamide concurrent with combination trastuzumab and pertuzumab for three cycles followed by docetaxel and the combination for three cycles (Arm A); with fluorouracil, epirubicin and cyclophosphamide alone for three cycles followed by docetaxel with the combination for three cycles (Arm B); or with docetaxel, carboplatin and trastuzumab with pertuzumab for six cycles (Arm C) [43]. The pCRs in the breast and lymph nodes were 50.7\% (Arm A), 45.3\% (Arm B) and 51.9\% (Arm C). The study was not intended to evaluate the superiority of any trial arm and the combination of trastuzumab and pertuzumab was generally well tolerated.

In 2013 the US FDA provided an accelerated approval for the use of pertuzumab in combination with trastuzumab and chemotherapy for the neoadjuvant treatment of HER2-positive locally advanced, inflammatory or earlystage breast cancer (either $>2 \mathrm{~cm}$ in diameter or nodepositive) as part of complete treatment regimen for early breast cancer [44]. This approval was based on the results of phase II NeoSphere [19] and was supported by phase II study TRYPHAENA trials [43], added to the fact that there was an already demonstrated improvement in OS in the metastatic setting (based on the CLEOPATRA study [18]). This represented the first regimen approved by the US FDA specifically for neoadjuvant treatment of breast cancer, although full approval will depend on additional data related to EFS in the adjuvant setting, which will be based on the data from the APHINITY trial (expected around 2016 or 2017; NCT01358877).

\section{Dual blockade with antibody-drug conjugate and targeted therapy}

Even with dual blockade, there is a subset of patients that do not achieve pCR or have early progression $[19,42,43]$. In the hope of improving efficacy, studies of ADC-containing dual blockade are ongoing.

\section{T-DM1 and pertuzumab}

Preclinical studies

In MDA-175 cells, the combination of T-DM1 and pertuzumab showed enhanced antiproliferative activity and induction of apoptosis compared with either agent alone
[45]. In Calu-3, BT-474 and SK-BR-3 cells, T-DM1 was more active than pertuzumab and the combination was more potent than the single drugs. Previous studies have noted that the presence of the HER3 ligand heregulin $(\mathrm{NRG}-1 \beta)$ can reduce the cytotoxic activity of T-DM1 in a subset of breast cancer cell lines. The addition of pertuzumab fully restored the apoptotic response to T-DM1, providing additional evidence for the rationale of combining pertuzumab and T-DM1 [45].

The combination of T-DM1 and pertuzumab in vivo in the KPL-4 breast tumor xenografts resulted in statistically significant inhibition of tumor growth as compared with the single-agent treatment group. Sustained tumor growth inhibition was also seen for the duration of the study (88 days) compared with 40 days with T-DM1 alone [45].

\section{Clinical studies}

A global phase Ib/II study was conducted to investigate the safety and efficacy of T-DM1 and pertuzumab. The phase Ib results demonstrated acceptable tolerability and promising efficacy (response rate $44.4 \%$ ) in heavily pretreated MBC patients [45]. The MARIANNE trial is a phase III study in first-line HER2-positive MBC patients that randomizes patients to receive trastuzumab plus a taxane versus T-DM1 plus placebo versus T-DM1 plus pertuzumab (results expected late 2014 or early 2015; NCT01120184).

\section{T-DM1 and lapatinib}

\section{Preclinical studies}

Single-agent trastuzumab, lapatinib or T-DM1 and the combination of trastuzumab plus lapatinib and the combination of T-DM1 plus lapatinib were studied in vivo in the BT474-me breast cancer cell line (J Chang, unpublished data). Tumors treated with single-agent T-DM1 and those treated with the combination of trastuzumab plus lapatinib showed a similar reduction in tumor size. The most significant tumor size reduction was observed in the group treated with the combination of TDM-1 plus lapatinib, where tumor regression was observed in the first 2 days and was significantly superior to the regression observed in the tumors treated with trastuzumab plus lapatinib combination (Figure 1a).

BT474 and SKBR3 cell lines were treated with singleagent trastuzumab, lapatinib, or T-DM1 or with the combination of lapatinib and T-DM1 (J Chang, unpublished data). Proliferation was reduced by lapatinib and lapatinib combination in both cell lines (Figure 1b). Single-agent trastuzumab, single-agent TDM-1 and the combination of TDM-1 plus lapatinib demonstrated significantly induced apoptosis in both cell lines (Figure 1c). These data support the different mechanisms of action of lapatinib versus 
(a)

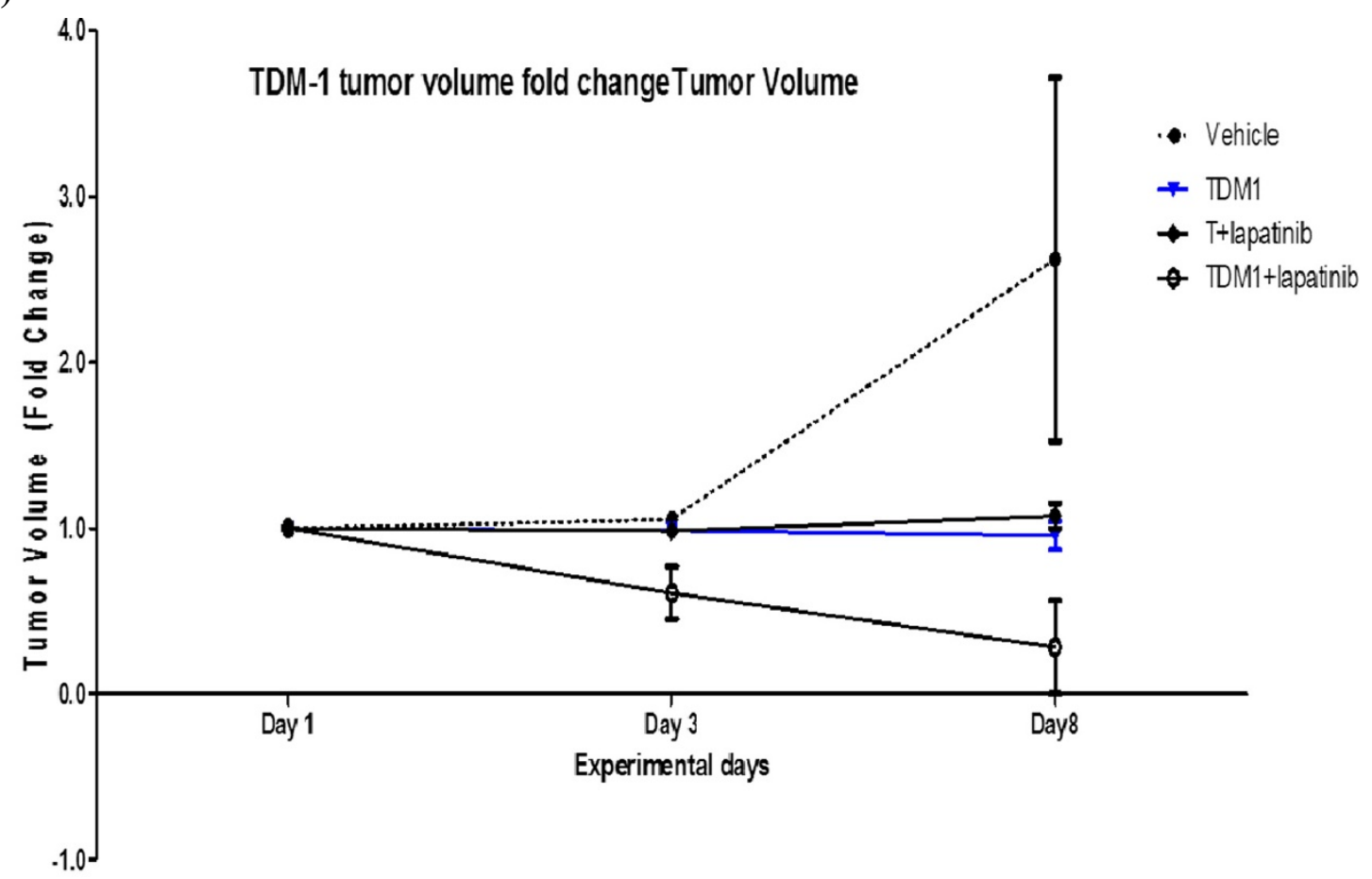

(b)

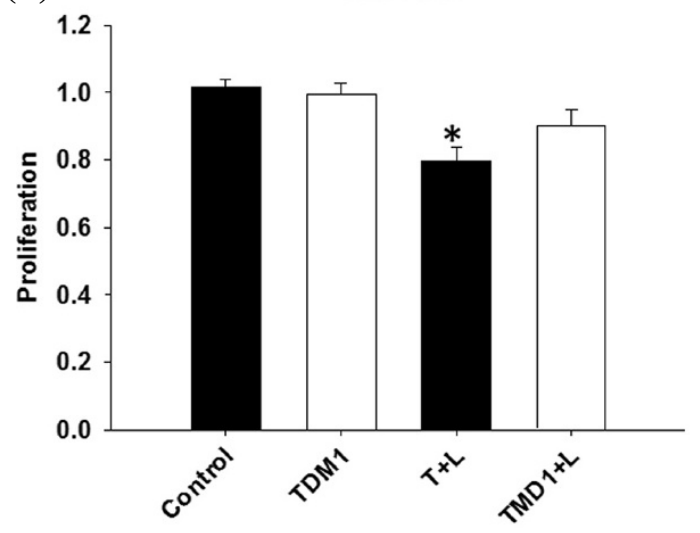

(c)

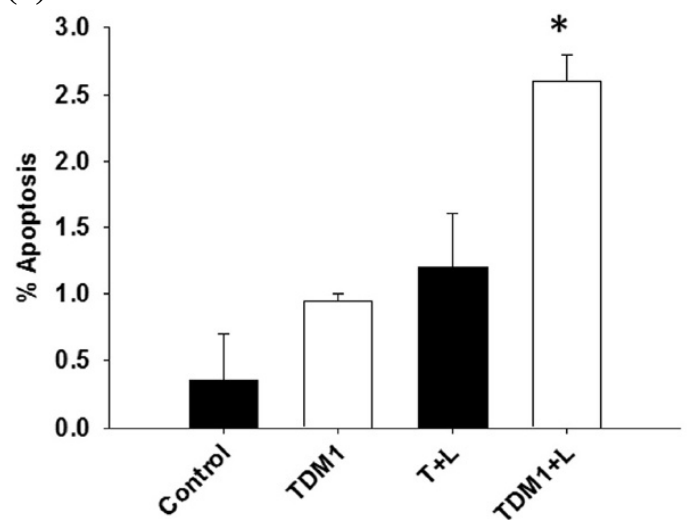

BT474
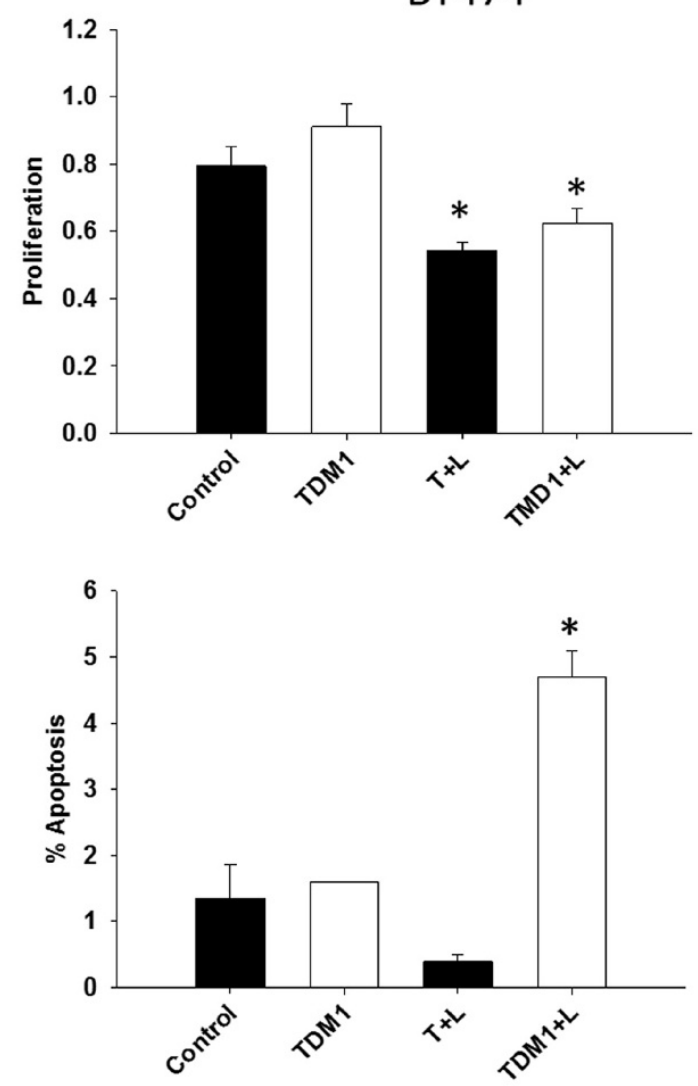

Figure 1 (See legend on next page.) 
(See figure on previous page.)

Figure 1 Dual blockade with antibody-drug conjugate and targeted therapy. (a) SCID Beige mice were injected with 1 million cells per mouse of the estrogen receptor-positive, human epidermal growth factor receptor (HER)-positive cell line BT474-m1. These animals were randomized into six groups and treated with: vehicle control; trastuzumab (5 mg/kg once weekly); lapatinib (100 mg/kg daily); ado-trastuzumab-emtansine (TDM1; 5 mg/kg weekly); trastuzumab (5 mg/kg once weekly) + lapatinib (100 mg/kg daily); or TDM1 (5 mg/kg weekly) + lapatinib (100 mg/kg daily). Tumor volume fold-change will be measured twice weekly post-treatment. (b,c) BT474 and SKBR3 HER2-positive cell lines were treated with the following: vehicle control; TDM1 (1 mg/ml); trastuzumab (10 mg/ml) + lapatinib (10 mM); or TDM1 (1 mg/ml) + lapatinib (10 mM). Cells were assessed for proliferation and apoptosis post-treatment. *Data analyzed by one way analysis of variance followed by Tukey analysis for a pairwise comparison of different groups, $P<0.05 ; \mathrm{T}$, trastuzumab; L, lapatinib. Data from J Chang, unpublished data.

trastuzumab versus T-DM1, thus indicating the potential for synergism with combinatorial treatments.

\section{Clinical studies}

Based on the preclinical data, a phase Ib study of lapatinib in combination with T-DM1 and nab-paclitaxel is currently ongoing. In a $3+3$ study design, the maximum tolerated dose was found to be T-DM1 $3.6 \mathrm{mg} / \mathrm{kg}$ intravenously every 3 weeks plus lapatinib $750 \mathrm{mg} /$ daily orally along with nab-paclitaxel $80 \mathrm{mg} / \mathrm{m}^{2}$ intravenously weekly [ClinicalTrials.gov: NCT02073916].

\section{Newer tyrosine kinase inhibitors of HER2}

Studies are ongoing into the combination of afatinib and trastuzumab or the combination of neratinib and trastuzumab in the metastatic and neoadjuvant settings.

\section{Trastuzumab and afatinib}

Afatinib is a tyrosine kinase inhibitor with activity against HER2 and endothelial growth factor receptor. In a phase II trial of patients with HER2-positive MBC that had progressed following trastuzumab, a $10 \%$ response rate $(4 / 41$ patients) was observed with afatinib, demonstrating the activity of this agent in this refractory metastatic setting [46].

\section{Trastuzumab and neratinib}

Neratinib is an oral irreversible inhibitor of endothelial growth factor receptor and HER2 tyrosine kinases. A phase II trial of single-agent neratinib showed a $24 \%$ response rate in $\mathrm{MBC}$ patients who had progression following trastuzumab and a 56\% response rate as firstline therapy [47]. Diarrhea occurred in 30\% of patients with prior trastuzumab treatment and $13 \%$ of patients with no prior trastuzumab treatment [47].

\section{Different subsets of HER2-positive breast cancers: hormone receptor-positive and hormone receptor-negative subsets}

Several completed neoadjuvant trials have demonstrated significant differences in the rates of pCR among hormone receptor-positive and hormone receptor-negative subsets, with higher $\mathrm{pCR}$ rates (at least twice as high) in the hormone receptor-negative subsets (Table 4). The highest pCR rates were seen in the HER2-enhanced subset, with the lowest response rates noted in the luminal subsets [37]. The duration of neoadjuvant therapy is

Table 4 Pathologic complete response with dual HER2 regimen in hormone receptor-negative versus hormone receptor-positive subsets of HER2 positive breast cancer: an exploratory comparison

\begin{tabular}{|c|c|c|c|}
\hline Study & $\begin{array}{l}\text { pCR breast and lymph } \\
\text { node combination } \mathrm{T}+\mathrm{L} \\
\text { or } \mathrm{T}+\mathrm{P}(\%)\end{array}$ & $\begin{array}{l}\text { pCR breast and lymph node } \\
\text { combination } T+L \text { or } T+P \\
\text { ER-negative subset }(\%)\end{array}$ & $\begin{array}{l}\text { pCR breast and lymph node } \\
\text { combination } T+L \text { or } T+P \\
\text { ER-positive subset }(\%)\end{array}$ \\
\hline NeoALTTO $[12,34]$ & 46.8 & 61.3 & 41.6 \\
\hline CHER-LOB [35] & 46.7 & 41.3 & 28.8 \\
\hline NSABP 41 [36] & 60.2 & 55.6 & 73 \\
\hline CALGB 40601 [37] & 52 & 66 & 42 \\
\hline TRIO US B07 [38] & 52 & 67 & 40 \\
\hline NeoSphere [19,32] & 39.3 & 63.2 & 26 \\
\hline \multirow[t]{2}{*}{ TRYPHAENA [43] } & 50.7 FECPH $\rightarrow \mathrm{DPH}$ & 79.4 & 46.2 \\
\hline & 51.9 TCHP & 83.8 & 50 \\
\hline LPT 109096 [39] & 74 & $N R$ & $N R$ \\
\hline
\end{tabular}

$\mathrm{DPH}$, docetaxel, pertuzumab and trastuzumab; ER, estrogen receptor; FECPH, fluorouracil, epirubicin, cyclophosphamide, pertuzumab and trastuzumab; HER, human epidermal growth factor receptor; L, lapatinib; NR, not reported; P, pertuzumab; $\mathrm{PCR}$, pathologic complete response; T, trastuzumab; TCHP, docetaxel, carboplatin, trastuzumab and pertuzumab. 
relatively short and recent studies have shown pCR correlation with progression-free survival in hormone receptornegative subsets rather than hormone receptor-positive subsets, so the true benefit of dual therapy in hormone receptor-positive patients should be assessed with longer term therapy. This benefit is currently being assessed with an extension study of lapatinib plus trastuzumab with or without endocrine therapy (HELEX) TBCRC 023 [ClinicalTrials.gov: NCT00999804].

\section{Conclusion}

Therapies directed at HER2 establish a successful treatment paradigm, but de novo and acquired resistance exist. With the help of a neoadjuvant model, many studies have demonstrated that single-agent HER2-targeted therapies are efficacious but response is incomplete. Large randomized clinical trials have also demonstrated that dual HER2 targeted combinations with trastuzumab/lapatinib and trastuzumab/pertuzumab are synergistic. Recently, the ADC T-DM1 has been approved for the treatment of HER2-overexpressing MBC. Combination of dual HER2-targeted treatments with T-DM1 and lapatinib or pertuzumab may demonstrate improved efficacy in patients. The results of the ALTTO trial highlight the challenge of determining which patients need multiple targeted therapies. In the future, correlative science embedded within the clinical trials will be invaluable in developing personalized therapy. Studies aimed at characterizing the different genetic alterations associated with resistance to HER2-directed therapies may lead to the discovery of new targets that may overcome resistance.

Note: This article is part of a series on 'Recent advances in breast cancer treatment', edited by Jenny Chang. Other articles in this series can be found at http://breast-cancer-research. com/series/treatment.

\section{Abbreviations}

ADC: Antibody-drug conjugate; DFS: Disease-free survival; EFS: Event-free survival; ER: Estrogen receptor; FDA: Food and Drug Administration; HER: Human epidermal growth factor receptor; HR: Hazard ratio; MBC: Metastatic breast cancer; OS: Overall survival; pCR: Pathologic complete response; PI3K: Phosphoinositide-3-kinase; PTEN: Phosphatase and tensin homolog; T-DM1: Ado-trastuzumab-emtansine.

\section{Competing interests}

The authors declare that they have no competing interests.

\section{Acknowledgements}

The authors thank Dr Madhumita Ghosh for editing the final manuscript. This study was supported in part by the Breast Cancer Research Foundation, $\mathrm{NIH}$ R01 CA138197 (JCC) and NIH R01 CA112305 (JCC) from the National Cancer Institute; by Golfers against Cancer; by the Emily Herrmann research fund; by a grant-in-aid from Glaxo Smith Kline, Komen Promise for the Cure KG081694 (JCC); and by National Institutes of Health NIH U54 CA 149196.

\section{Author details}

'Houston Methodist Cancer Center, 6445 Main Street, P21-34, Houston, TX 77030, USA. ${ }^{2}$ Department of Medicine, Weill Cornell Medical College, 1300 York Avenue, New York, NY 10065, USA. ${ }^{3}$ Division of Hemotology and Oncology, College of Medicine, Mayo Clinic, 4500 San Pablo Rd S. Jacksonville, FL 32224, USA.

Published online: 01 August 2014

\section{References}

1. Romond EH, Perez EA, Bryant J, Suman VJ, Geyer CE Jr, Davidson NE, Tan-Chiu E, Martino S, Paik S, Kaufman PA, Swain SM, Pisansky TM, Fehrenbacher L, Kutteh LA, Vogel VG, Visscher DW, Yothers G, Jenkins RB, Brown AM, Dakhil SR, Mamounas EP, Lingle WL, Klein PM, Ingle JN, Wolmark $\mathrm{N}$ : Trastuzumab plus adjuvant chemotherapy for operable HER2-positive breast cancer. N Engl J Med 2005, 353:1673-1684.

2. Slamon DJ, Leyland-Jones B, Shak S, Fuchs H, Paton V, Bajamonde A, Fleming T, Eiermann W, Wolter J, Pegram M, Baselga J, Norton L: Use of chemotherapy plus a monoclonal antibody against HER2 for metastatic breast cancer that overexpresses HER2. N Engl J Med 2001, 344:783-792.

3. Arteaga CL, Sliwkowski MX, Osborne CK, Perez EA, Puglisi F, Gianni L: Treatment of HER2-positive breast cancer: current status and future perspectives. Nat Rev Clin Oncol 2012, 9:16-32.

4. Cho HS, Mason K, Ramyar KX, Stanley AM, Gabelli SB, Denney DW Jr, Leahy DJ: Structure of the extracellular region of HER2 alone and in complex with the herceptin Fab. Nature 2003, 421:756-760.

5. Riese DJ 2nd, Stern DF: Specificity within the EGF family/ErbB receptor family signaling network. Bioessays 1998, 20:41-48.

6. Amundadottir $L T$, Leder P: Signal transduction pathways activated and required for mammary carcinogenesis in response to specific oncogenes. Oncogene 1998, 16:737-746.

7. Okano J, Gaslightwala I, Birnbaum MJ, Rustgi AK, Nakagawa H: Akt/protein kinase $B$ isoforms are differentially regulated by epidermal growth factor stimulation. J Biol Chem 2000, 275:30934-30942.

8. Rusnak DW, Affleck K, Cockerill SG, Stubberfield C, Harris R, Page M, Smith KJ, Guntrip SB, Carter MC, Shaw RJ, Jowett A, Stables J, Topley P, Wood ER, Brignola PS, Kadwell SH, Reep BR, Mullin RJ, Alligood KJ, Keith BR, Crosby RM, Murray DM, Knight WB, Gilmer TM, Lackey K: The characterization of novel, dual ErbB-2/EGFR, tyrosine kinase inhibitors: potential therapy for cancer. Cancer Res 2001, 61:7196-7203.

9. Cameron D, Casey M, Oliva C, Newstat B, Imwalle B, Geyer CE: Lapatinib plus capecitabine in women with HER-2-positive advanced breast cancer: final survival analysis of a phase III randomized trial. Oncologist 2010, 15:924-934.

10. Geyer CE, Forster J, Lindquist D, Chan S, Romieu CG, Pienkowski T, Jagiello-Gruszfeld A, Crown J, Chan A, Kaufman B, Skarlos D, Campone M, Davidson N, Berger M, Oliva C, Rubin SD, Stein S, Cameron D: Lapatinib plus capecitabine for HER2-positive advanced breast cancer. N Engl J Med 2006, 355:2733-2743.

11. Agus DB, Gordon MS, Taylor C, Natale RB, Karlan B, Mendelson DS, Press MF, Allison DE, Sliwkowski MX, Lieberman G, Skarlos D, Campone M, Davidson N, Berger M, Oliva C, Rubin SD, Stein S, Cameron D: Phase I clinical study of pertuzumab, a novel HER dimerization inhibitor, in patients with advanced cancer. J Clin Oncol 2005, 23:2534-2543.

12. Baselga J, Bradbury I, Eidtmann H, Di Cosimo S, de Azambuja E, Aura C, Gomez H, Dinh P, Fauria K, Van Dooren V, Aktan G, Goldhirsch A, Chang TW Horvath Z, Coccia-Portugal M, Domont J, Tseng LM, Kunz G, Sohn JH, Semiglazov V, Lerzo G, Palacova M, Probachai V, Pusztai L, Untch M, Gelber RD, Piccart-Gebhart M: Lapatinib with trastuzumab for HER2-positive early breast cancer (NeoALTTO): a randomised, open-label, multicentre, phase 3 trial. Lancet 2012, 379:633-640.

13. Verma S, Miles D, Gianni L, Krop IE, Welslau M, Baselga J, Pegram M, Oh DY, Dieras V, Guardino E, Fang L, Lu MW, Olsen S, Blackwell K: Trastuzumab emtansine for HER2-positive advanced breast cancer. N Engl J Med 2012, 367:1783-1791.

14. Wildiers H, Kim SB, Gonzalez-Martin A, LoRusso PM, Ferrero JM, Smitt M, Yu R, Leung A, Krop IE: T-DM1 for HER2-positive metastatic breast cancer (MBC): primary results from TH3RESA, a phase 3 study of T-DM1 vs treatment of physician's choice [abstract]. Eur J Cancer 2013, 49:Abstract LBA15. 
15. Slamon DJ, Eiermann W, Robert N, Pienkowski T, Martin M, Press M, Mackey J, Glaspy J, Chan A, Pawlicki M, Pinter T, Valero V, Liu MC, Sauter G, von Minckwitz G, Visco F, Bee V, Buyse M, Bendahmane B, Tabah-Fisch I, Lindsay MA, Riva A, Crown J: Adjuvant trastuzumab in HER2-positive breast cancer. N Engl J Med 2011, 365:1273-1283.

16. Cameron D, Casey M, Press M, Lindquist D, Pienkowski T, Romieu CG, Chan S, Jagiello-Gruszfeld A, Kaufman B, Crown J, Chan A, Campone M, Viens P, Davidson N, Gorbounova V, Raats Jl, Skarlos D, Newstat B, Roychowdhury D, Paoletti P, Oliva C, Rubin S, Stein S, Geyer CE: A phase III randomized comparison of lapatinib plus capecitabine versus capecitabine alone in women with advanced breast cancer that has progressed on trastuzumab: updated efficacy and biomarker analyses. Breast Cancer Res Treat 2008, 112:533-543.

17. Kaufman B, Mackey JR, Clemens MR, Bapsy PP, Vaid A, Wardley A, Tjulandin S, Jahn M, Lehle M, Feyereislova A, Revil C, Jones A: Trastuzumab plus anastrozole versus anastrozole alone for the treatment of postmenopausal women with human epidermal growth factor receptor 2-positive, hormone receptor-positive metastatic breast cancer: results from the randomized phase III TAnDEM study. J Clin Oncol 2009, 27:5529-5537.

18. Swain SM, Kim SB, Cortes J, Ro J, Semiglazov V, Campone M, Ciruelos E, Ferrero JM, Schneeweiss A, Knott A, Clark E, Ross G, Benyunes MC, Baselga J: Pertuzumab, trastuzumab, and docetaxel for HER2-positive metastatic breast cancer (CLEOPATRA study): overall survival results from a randomised, double-blind, placebo-controlled, phase 3 study. Lancet Oncol 2013, 14:461-471.

19. Gianni L, Pienkowski T, Im YH, Roman L, Tseng LM, Liu MC, Lluch A, Staroslawska E, de la Haba-Rodriguez J, Im SA, Pedrini JL, Poirier B, Morandi P, Semiglazov V, Srimuninnimit V, Bianchi G, Szado T, Ratnayake J, Ross G, Valagussa P: Efficacy and safety of neoadjuvant pertuzumab and trastuzumab in women with locally advanced, inflammatory, or early HER2-positive breast cancer (NeoSphere): a randomised multicentre, open-label, phase 2 trial. Lancet Oncol 2012, 13:25-32.

20. Sergina NV, Rausch M, Wang D, Blair J, Hann B, Shokat KM, Moasser MM: Escape from HER-family tyrosine kinase inhibitor therapy by the kinase-inactive HER3. Nature 2007, 445:437-441.

21. Nagata $Y$, Lan KH, Zhou X, Tan M, Esteva FJ, Sahin AA, Klos KS, Li P, Monia BP, Nguyen NT, Hortobagyi GN, Hung MC, Yu D: PTEN activation contributes to tumor inhibition by trastuzumab, and loss of PTEN predicts trastuzumab resistance in patients. Cancer Cell 2004, 6:117-127

22. Berns K, Horlings HM, Hennessy BT, Madiredjo M, Hijmans EM, Beelen K, Linn SC, Gonzalez-Angulo AM, Stemke-Hale K, Hauptmann M, Beijersbergen RL, Mills GB, van de Vijver MJ, Bernards R: A functional genetic approach identifies the PI3K pathway as a major determinant of trastuzumab resistance in breast cancer. Cancer Cell 2007, 12:395-402.

23. Scaltriti M, Rojo F, Ocana A, Anido J, Guzman M, Cortes J, Di Cosimo S, Matias-Guiu X, Ramon Y, Cajal S, Arribas J, Baselga J: Expression of p95HER2, a truncated form of the HER2 receptor, and response to anti-HER2 therapies in breast cancer. J Natl Cancer Inst 2007, 99:628-638.

24. Nagy P, Friedlander E, Tanner M, Kapanen Al, Carraway KL, Isola J, Jovin TM: Decreased accessibility and lack of activation of ErbB2 in JIMT-1, a herceptin-resistant, MUC4-expressing breast cancer cell line. Cancer Res 2005, 65:473-482.

25. Dave B, Migliaccio I, Gutierrez MC, Wu MF, Chamness GC, Wong H, Narasanna A, Chakrabarty A, Hilsenbeck SG, Huang J, Rimawi M, Schiff R, Arteaga C, Osborne CK, Chang JC: Loss of phosphatase and tensin homolog or phosphoinositol-3 kinase activation and response to trastuzumab or lapatinib in human epidermal growth factor receptor 2-overexpressing locally advanced breast cancers. J Clin Oncol 2011, 29:166-173.

26. Perez EA, Dueck AC, McCullough AE, Chen B, Geiger XJ, Jenkins RB, Lingle WL, Davidson NE, Martino S, Kaufman PA, Kutteh LA, Sledge GW, Harris LN, Gralow JR, Reinholz MM: Impact of PTEN protein expression on benefit from adjuvant trastuzumab in early-stage human epidermal growth factor receptor 2-positive breast cancer in the North Central Cancer Treatment Group N9831 trial. J Clin Oncol 2013, 31:2115-2122.

27. Liu L, Greger J, Shi H, Liu Y, Greshock J, Annan R, Halsey W, Sathe GM, Martin AM, Gilmer TM: Novel mechanism of lapatinib resistance in HER2-positive breast tumor cells: activation of AXL. Cancer Res 2009, 69:6871-6878
28. Xia W, Bacus S, Hegde P, Husain I, Strum J, Liu L, Paulazzo G, Lyass L, Trusk P, Hill J, Harris J, Spector NL: A model of acquired autoresistance to a potent ErbB2 tyrosine kinase inhibitor and a therapeutic strategy to prevent its onset in breast cancer. Proc Natl Acad Sci U S A 2006 103:7795-7800.

29. Eichhorn PJ, Gili M, Scaltriti M, Serra V, Guzman M, Nijkamp W, Beijersbergen RL, Valero V, Seoane J, Bernards R, Baselga J: Phosphatidylinositol 3-kinase hyperactivation results in lapatinib resistance that is reversed by the mTOR/phosphatidylinositol 3-kinase inhibitor NVP-BEZ235. Cancer Res 2008, 68:9221-9230.

30. Arpino G, Gutierrez C, Weiss H, Rimawi M, Massarweh S, Bharwani L, De Placido S, Osborne CK, Schiff R: Treatment of human epidermal growth factor receptor 2-overexpressing breast cancer xenografts with multiagent HER-targeted therapy. J Natl Cancer Inst 2007, 99:694-705.

31. Rimawi MF, Wiechmann LS, Wang YC, Huang C, Migliaccio I, Wu MF Gutierrez C, Hilsenbeck SG, Arpino G, Massarweh S, Ward R, Soliz R, Osborne CK, Schiff R: Reduced dose and intermittent treatment with lapatinib and trastuzumab for potent blockade of the HER pathway in HER2/neu-overexpressing breast tumor xenografts. Clin Cancer Res 2011, 17:1351-1361.

32. Rimawi MF, Mayer IA, Forero A, Nanda R, Goetz MP, Rodriguez AA, Pavlick AC, Wang T, Hilsenbeck SG, Gutierrez C, Schiff R, Osborne CK, Chang JC: Multicenter phase II study of neoadjuvant lapatinib and trastuzumab with hormonal therapy and without chemotherapy in patients with human epidermal growth factor receptor 2-overexpressing breast cancer: TBCRC 006. J Clin Oncol 2013, 31:1726-1731.

33. Blackwell KL, Burstein HJ, Storniolo AM, Rugo H, Sledge G, Koehler M, Ellis C, Casey M, Vukelja S, Bischoff J, Baselga J, O'Shaughnessy J: Randomized study of lapatinib alone or in combination with trastuzumab in women with ErbB2-positive, trastuzumab-refractory metastatic breast cancer. J Clin Oncol 2010, 28:1124-1130.

34. Piccart-Gebhart MHA, de Azambuja E, Di Cosimo S, Swaby R, Untch M, Jackisch C, Lang I, Smith I, Boyle F, Xu B, Barrios C, Gelber R, Eidtmann H, Baselga J: The association between event-free survival and pathological complete response to neoadjuvant lapatinib, trastuzumab or their combination in HER2-positive breast cancer. Survival follow-up analysis of the NeOALTTO study (BIG 1-06). San Antonio; 2013: Paper presented at San Antonio Breast Cancer Symposium; 2013.

35. Guarneri V, Frassoldati A, Bottini A, Cagossi K, Bisagni G, Sarti S, Ravaioli A, Cavanna L, Giardina G, Musolino A, Untch M, Orlando L, Artioli F, Boni C, Generali DG, Serra P, Bagnalasta M, Marini L, Piacentini F, D'Amico R, Conte $P$ : Preoperative chemotherapy plus trastuzumab, lapatinib, or both in human epidermal growth factor receptor 2-positive operable breast cancer: results of the randomized phase II CHER-LOB study. J Clin Oncol 2012, 30:1989-1995.

36. Robidoux A, Tang G, Rastogi P, Geyer CE Jr, Azar CA, Atkins JN, Fehrenbacher L, Bear HD, Baez-Diaz L, Sarwar S, Margolese RG, Farrar WB, Brufsky AM, Shibata HR, Bandos H, Paik S, Costantino JP, Swain SM, Mamounas EP, Wolmark N: Lapatinib as a component of neoadjuvant therapy for HER2-positive operable breast cancer (NSABP protocol B-41): an open-label, randomised phase 3 trial. Lancet Oncol 2013, 14:1183-1192

37. Carey LA, Berry DA, Ollila D, Harris L, Krop IE, Weckstein D, Lynn Henry N, Anders CK, Cirrincione C, Winer EP, Perou CM, Hudis C: Clinical and translational results of CALGB 40601: a neoadjuvant phase III trial of weekly paclitaxel and trastuzumab with or without lapatinib for HER2-positive breast cancer [abstract]. J Clin Oncol 2013, 31:Abstract 500.

38. Hurvitz S, Miller JM, Dichmann R, Perez AT, Patel R, Zehngebot LM, Allen $H_{\text {, }}$ Bosserman LD, DiCarlo BA, Kennedy A, Giuliano A, Calfa CJ, Molthrop DC, Mani A, Dering J, Wang H-J, Adams B, Martinez D, Chen H-W, Zoeller J, Brugge JS, Slamon DJ: Final analysis of a phase II, 3-arm, randomized trial of neoadjuvant trastuzumab or lapatinib or combination of trastuzumab and lapatinib, followed by 6 cycles of docetaxel and carboplatin with trastuzumab and/or lapatinib in patients with HER2 + breast cancer (TRIO US B07). San Antonio, Texas, USA: Paper presented at San Antonio Breast Cancer Symposium; 2013.

39. Holmes FA, Espina VA, Liotta LA, Danso MA, Gallagher Rl, Mclntyre K, Osborne CRC, Mahoney JM, Florance AM, Anderson TC, O'Shaughnessy J: Correlation of molecular effects and pathologic complete response to preoperative lapatinib and trastuzumab, separately and combined prior 
to neoadjuvant breast cancer chemotherapy [abstract]. J Clin Oncol 2011, 29:Abstract 506.

40. Piccart-Gebhart MJ, Homles AP, Baselga J, Azambuja EA, Dueck AC, Viale G, Zujewski JA, Goldhirsch A, Santillana S, Pritchard KI, Wolff AC, Jackisch C, Lang I, Untch M, Smith IE, Boyle F, Xu B, Gomez HL, Gelber RD, Perez EA: First results from the phase III ALTTO trial (BIG 2-06; NCCTG [Alliance] N063D) comparing one year of anti-HER2 therapy with lapatinib alone $(\mathrm{L})$, trastuzumab alone $(\mathrm{T})$, their sequence $(\mathrm{T} \rightarrow \mathrm{L})$, or their combination $(\mathrm{T}+\mathrm{L})$ in the adjuvant treatment of HER2-positive early breast cancer (EBC) [abstract LBA4]. J Clin Oncol 2014, 32:5s,

41. Scheuer W, Friess T, Burtscher H, Bossenmaier B, Endl J, Hasmann M: Strongly enhanced antitumor activity of trastuzumab and pertuzumab combination treatment on HER2-positive human xenograft tumor models. Cancer Res 2009, 69:9330-9336.

42. Baselga J, Cortes J, Kim SB, Im SA, Hegg R, Im YH, Roman L, Pedrini JL, Pienkowski T, Knott A, Clark E, Benyunes MC, Ross G, Swain SM, CLEOPATRA Study Group: Pertuzumab plus trastuzumab plus docetaxel for metastatic breast cancer. N Engl J Med 2012, 366:109-119.

43. Schneeweiss A, Chia S, Hickish T, Harvey V, Eniu A, Hegg R, Tausch C Seo JH, Tsai YF, Ratnayake J, McNally V, Ross G, Cortes J: Pertuzumab plus trastuzumab in combination with standard neoadjuvant anthracyclinecontaining and anthracycline-free chemotherapy regimens in patients with HER2-positive early breast cancer: a randomized phase II cardiac safety study (TRYPHAENA). Ann Oncol 2013, 24:2278-2284

44. FDA Approves Perjeta for Neoadjuvant Breast Cancer Treatment [News Release]. http://www.fda.gov/NewsEvents/Newsroom/PressAnnouncements/ ucm370393.htm?source =govdelivery\&utm_medium=email\&utm_source= govdelivery] Accessed October 16, 2013

45. Phillips GD, Fields $C T$, Li G, Dowbenko D, Schaefer G, Miller $K$, Andre F, Burris HA 3rd, Albain KS, Harbeck N, Dieras V, Crivellari D, Fang L, Guardino E, Olsen SR, Crocker LM, Sliwkowski MX: Dual targeting of HER2-positive cancer with trastuzumab emtansine and pertuzumab: critical role for neuregulin blockade in antitumor response to combination therapy. Clin Cancer Res 2014, 20:456-468.

46. Lin NU, Winer EP, Wheatley D, Carey LA, Houston S, Mendelson D, Munster P, Frakes L, Kelly S, Garcia AA, Cleator S, Uttenreuther-Fischer M, Jones H, Wind S, Vinisko R, Hickish T: A phase II study of afatinib (BIBW 2992), an irreversible ErbB family blocker, in patients with HER2-positive metastatic breast cancer progressing after trastuzumab. Breast Cancer Res Treat 2012, 133:1057-1065.

47. Burstein $H J$, Sun $Y$, Dirix LY, Jiang Z, Paridaens R, Tan AR, Awada A, Ranade A, Jiao S, Schwartz G, Abbas R, Powell C, Turnbull K, Vermette J, Zacharchuk C, Badwe R: Neratinib, an irreversible ErbB receptor tyrosine kinase inhibitor, in patients with advanced ErbB2-positive breast cancer. J Clin Oncol 2010, 28:1301-1307.

doi:10.1186/s13058-014-0419-5

Cite this article as: Patel et al: Dual HER2 blockade: preclinical and clinical data. Breast Cancer Research 2014 16:419. 